\title{
Improving the level of psychological preparation of potential drivers
}

\author{
Vladimir Zelikov ${ }^{1}$, Galina Klimova ${ }^{1}$, Alexander Artemov ${ }^{1}$ and Natalia Zelikova ${ }^{1}$ \\ ${ }^{1}$ Voronezh State Forestry Engineering University named after G.F. Morozov, 394087 Voronezh, \\ Russian Federation
}

\begin{abstract}
The article provides methods of improving the quality of psychological preparation have been considered to ensure road transport safety. A set of measures has been proposed to reduce the number of emergency situations at the following stages: admission to a driving school (stage 1), during the period of study (stage 2), at the beginning of professional activity (stage 3 ) and in the process of professional activity (stage 4). The mechanism of assessment formation of professional driver suitability by psychophysiological indicators for domestic and international trips in modern traffic management conditions has been considered. The methodology for evaluating professional driver suitability and, accordingly, the selection of drivers by psychological indicators has been suggested.
\end{abstract}

One of the main reasons of road traffic accidents (RTA) is deliberate violation of Road Traffic Regulations (RTR), both by drivers and pedestrians. Over $75 \%$ of all road accidents are associated with violations of the Regulations by vehicle drivers. A part of such violations is sometimes committed due to a low level of transport culture. The road safety problem is exacerbated by the fact that most of the injuries are received by the working-age population aged 25 to 45 years. According to Federal State Statistics Service (Russia), in 2019 , the overall mortality rate of victims of road accidents is 12 times higher than that of injuries as a result of other accidents. Disability is 6 times higher, and victims need hospitalization 7 times more often. About 17 thousand people died on the roads of the Russian Federation in 2019. Moreover, more than 5\% of those injured remain disabled for life. Road accidents mean not only damage to human health and environment, but also significant material losses.

The main factors affecting the accident rate include the following: insufficient attention to improving the organization of road traffic at the federal and regional levels, i.e., lack of due responsibility and discipline of managers at all levels, as well as road users. Preventing the development of nihilism that a high accident rate of more than $90 \%$ depends on the behavior of road users makes it possible to make effective decisions aimed at increasing road safety.

Causes of accidents can be defined as a set of conditions and circumstances of the accident, the elimination of which would make the accident impossible. Providing road

\footnotetext{
*Corresponding author: author@email.org
} 
safety is an integrated approach to the problems to ensure the safety of all road users and acquires an "ethical" content, where the main value is a person and social stability.

Reducing the number of driver errors largely depends on timely and correct actions of drivers. Therefore, it is impossible to ensure road safety without solving the problem of driver reliability, which is understood as the totality of all physical and mental personality traits and their impact on the success of the driver's labor activity.

The vehicle fleet of the Russian Federation are mainly $75.8 \%$ of passenger cars. Therefore, it is not difficult to calculate the proportion of professional drivers. It is about $25 \%$ in relation to non-professional drivers of personal vehicles. If the drivers are professionals, they annually undergo advanced training on a 20 -hour program, and then work to improve professional skills among amateur drivers is not carried out after graduating from a driving school and obtaining a driving license. Only the system of fines and administrative penalties is updated and increased for violations of the rules of safe behavior on the roads $[1,2]$.

The consequences and peculiarities of the occurrence of an accident are always associated with a specific personality of the driver, contributing to the creation of an emergency. The analysis of the driver's behavior, in our opinion, allows a more complete study of road accidents, and raises the question of effective prevention of these incidents. The study of the psychological concept of driver related accidents is an important reserve for increasing the level of preventive activities in the field of road safety management [3. 4].

Social interpersonal relationships in society are governed by appropriate rules of conduct. In the road environment, compliance with the norms and rules of conduct by each road user is of particular importance, since non-compliance with the rules can lead to irreversible negative consequences. The behavior of drivers in a situation on the road is directly dependent on the individual psychological characteristics and objective factors of the current specific situation. So, analyzing the behavior of individual people, one can make an assumption about the propensity, due to a combination of personal properties, about their predisposition to create emergency situations $[5,6,7]$.

We consider it is necessary to conduct a study of the psychophysiological and personal qualities of a driver provoking dangerous, emergency situations or increasing the risk of an accident in road traffic by their behavior, clearly having deviations from the safety standard. It is important for a correct understanding of the individual psychological characteristics of drivers in order to ensure human safety in the conditions of professional activity and increase reliability. Until now, there is no appropriate optimal diagnostic material that enables to identify a predisposition to violation of human safety standards. Starting to consider and analyze the aspects that increase the risk in the field of road safety, it is necessary to pay attention to the existing driver training programmes, namely, issues related to the psychological preparation of drivers $[8,9,10,11]$.

In order to ensure the safety of road transport, the programmes can be proposed at the following stages: admission to a driving school (stage 1), during the training period (stage 2 ), at the beginning of professional activity (stage 3 ) and in the process of professional activity (stage 4). These include:

- A developed mechanism for the formation of an assessment of the professional driver suitability by psychophysiological indicators for domestic and international trips in modern traffic management conditions;

- Methodology for evaluating the criteria for professional driver suitability and, accordingly, the selection of drivers by psychological indicators;

- Comprehensive system of measures to increase psychological reliability using digital and information technologies, which makes it possible to increase the efficiency of the labor resources use. 
At the stage of admission and during the period of training in a driving school we propose an algorithm for selecting candidates for driving schools, taking into account the requirements for driving activities, which will enable to determine the psychophysiological signs of suitability, conditional suitability and unsuitability for the professional activity of drivers. Using digital technology this will give a good result in the training of drivers and in the process of their professional development, since it will be possible to determine the "vulnerable" psychological characteristics and "reference" compliance with the professional requirements for the psychophysiological characteristics of the driver (fig. 1).

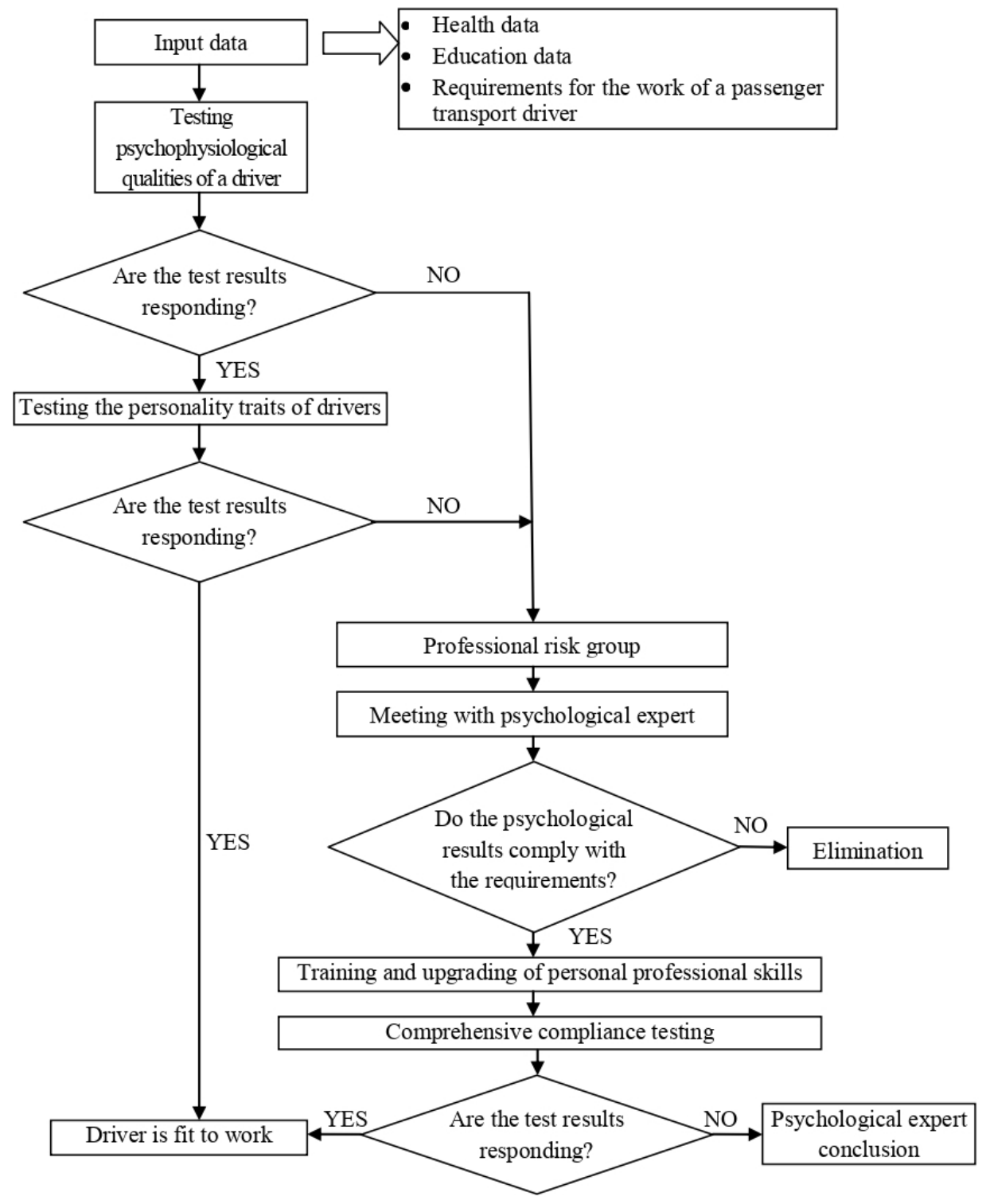

Fig. 1. Algorithm of professional and psychological selection of transport drivers at the beginning of professional activity (stage 3 ), and in the process of professional activity (stage 4). 
Fig. 2 shows the "Algorithm of professional selection, taking into account the assessment of the professional suitability of vehicle drivers."

This is a sequence of actions: creation of a databank for recording the professionally important qualities (PIQ) of drivers and control systems (a comprehensive method for examining the internal control system and substantiating the possibility of their work in transport). It provides not only an increase in the professional fitness of the driver and an increase in the quality of the transportation process, but also road safety.

Psychological selection is very important in the selection of driver personnel. Knowing certain psychophysiological characteristics of a person, it will be possible to recommend $\mathrm{him} / \mathrm{her}$ for a certain direction of activity (route) or for work within the enterprise. Taking into account the performance of drivers already working at the enterprise, it is rational to make a reshuffle of personnel, which consists in transferring drivers with low psychophysiological indicators from one route to another, more monotonous one. When transferring, it is important to take into account the state of health of the employee and his/her consent to the new job.

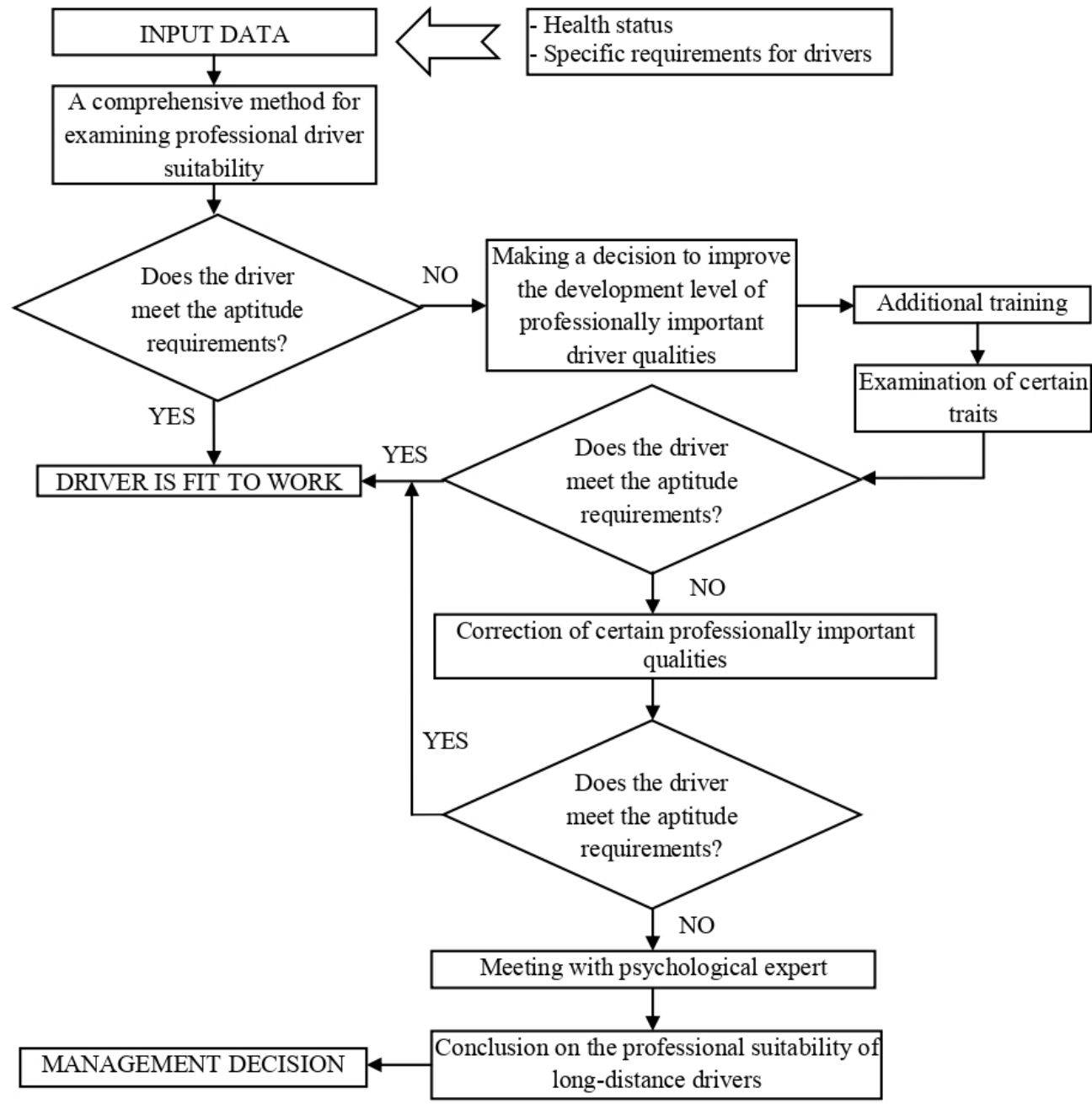

Fig. 2. Algorithm for professional selection, taking into account the assessment of professional driver suitability 
The above algorithms for professional selection and selection have common goals: monitoring and assessing the psychophysiological state of the driver; eliminating the causes of violations of the psychophysiological state, contributing to the occurrence of road accidents; replenishing the database on individual psychophysiological qualities about each candidate in the driver at the first stage, or already about the condition of a professional driver. Instrumental control is offered to improve the professionally important qualities of drivers.

The recommended complex assessment methodology is shown in table 1.

Table 1. A set of research methods for professionally significant psychological and psychophysiological functions

\begin{tabular}{|c|c|c|}
\hline $\begin{array}{l}\text { Studied psychological and psycho } \\
\text { physiological functions and qualities }\end{array}$ & Research methods & Toolkit \\
\hline $\begin{array}{l}\text { 1. The level of intellectual development, } \\
\text { mental agility }\end{array}$ & $\begin{array}{l}\text { Raven's tests } 16 \mathrm{PF} \\
\text { Factor B }\end{array}$ & Raven's Matrices \\
\hline 2. Emotional stability, courage & 16PF Factor C & Questions of the 16PF \\
\hline $\begin{array}{l}\text { 3. Compliance, striving for trusting } \\
\text { relationships }\end{array}$ & 16PF Factor E & Questions of the 16PF \\
\hline 4. Prudence, seriousness, composure & 16PF Factor F & Questions of the 16PF \\
\hline 5. Moral normativeness, responsibility & 16PF Factor $\mathrm{G}$ & Questions of the 16PF \\
\hline $\begin{array}{l}\text { 6. Striving for high academic performance, } \\
\text { discipline }\end{array}$ & 16PF Factor $\mathrm{J}$ & Questions of the 16PF \\
\hline 7. Responsibility, sensitivity to comments & 16PF Factor $\mathrm{O}$ & Questions of the 16PF \\
\hline 8. Anxiety & $\begin{array}{l}\text { Taylor Manifest } \\
\text { Anxiety Scale }\end{array}$ & Questions of the test \\
\hline 9. Visual motor response & Reflexometry & $\begin{array}{l}\text { Complex of } \\
\text { programmes }\end{array}$ \\
\hline 10. Balance of nervous processes & $\begin{array}{c}\text { Reaction to a moving } \\
\text { object }\end{array}$ & $\begin{array}{l}\text { Complex of } \\
\text { programmes }\end{array}$ \\
\hline 11. Sense of timing & Estimating time periods & Stopwatch \\
\hline 12. The ability to perceive spatial segments & Eye sight measurement & Eye ruler, forms \\
\hline 13. Information processing speed & Correction task & $\begin{array}{l}\text { Blanks (Landolt C } \\
\text { symbol) }\end{array}$ \\
\hline 14. Stability of attention & Correction task & $\begin{array}{l}\text { Blanks (Landolt C } \\
\text { symbol) }\end{array}$ \\
\hline $\begin{array}{l}\text { 15. Attentional set-shifting, range of attention, } \\
\text { operative memory }\end{array}$ & Red and black table & Test blanks \\
\hline 16. Attention selection & Münsterberg's test & Test blanks \\
\hline 17. Short memory & Jacobs test & Set of figures \\
\hline 18. Physical training tests & & Sports equipment \\
\hline
\end{tabular}

The study of the listed qualities was carried out both by test methods and using specially developed computer programs. When making an opinion on professional suitability, along with the data of a psychophysiological examination, it is necessary to take into account the results of the performance of physical training tests.

The necessary technical means are presented to increase the psychological reliability of the vehicle driver. This is UPFT-1/30, PAKPF-02, ROFES complex (recorders for assessing the functional and emotional state of drivers); psychophysiological trainer TA-2 for increasing the level of psychological important qualities (PIQ).

Technical means for a qualitative assessment of the professional driver suitability (potential drivers) can be used. These are, for example, AIC Avtopraktika-exam or PAKPF02 or ROFES, which will enable to objectively assess the number and level of mistakes, 
made during the practical exam and will allow the psychologist, together with the instructor, to outline the ways to increase to the required level - individual training of each novice driver.

For the examination of drivers according to the specified method, a psychologist acts as an expert, who, with the help of technical means, gives an objective assessment of the condition of drivers and develops recommendations for their use on highways with different traffic conditions and duration of work.

The question of the psychological state of drivers in road conditions and their maximum consideration when organizing traffic was considered. These issues have particular scientific significance. An integrated system of measures will reduce the number of emergency systems, because an evolutionary approach to personality development (from professional point of view) affects the behavior and changes the attitude towards professional activity.

The developed system of measures is aimed at increasing the efficiency of the use of labor resources, the quality of transport management, and, accordingly, ensuring road safety using digital and information technology. The technology makes it possible to implement a high level of transport support for the interests of the national economy.

\section{References.}

1. V. Klyavin, A. Grinchenko, Y. Rizaeva, N. Bakhtina, N. Baryshev, Assessing the quality of route vehicle passenger transportation,Proceedings - 2020 2nd International Conference on Control Systems, Mathematical Modeling, Automation and Energy Efficiency, SUMMA 2 P. 772-776. (2020)

2. V. Korchagin, V. Klyavin, J. Rizayeva, V. Chernishov, N. Baryshev, A. Dvurechenskaya, Evaluation of road safety measures efficiency in conditions of uncertainty, International Science and Technology Conference "EarthScience" P. 052055. (2020)

3. E.V. Ageev, A.N. Novikov, E.S. Vinogradov, Application of electronic information and educational environment in the preparation of candidates, drivers of motor vehicles, The world of transport and technological machines No. 1 (72) P. 96-102. (2021)

4. L.A. Kravchenko, Zh.V. Dubinina, I.A. Bereka, Driver training system in a driving school, taking into account personal qualities, Bulletin of the Moscow Automobile and Road Construction State Technical University (MADI) No. 1 (56) P. 42-48. (2019)

5. V.Ya. Builenko, G.N. Klimova, V.A. Zelikov, Yu.V. Strukov, A.Yu. Artemov, Methodological approaches to improving the quality of training of drivers of motor vehicles, Science and technology in the road industry No. 3 (85) P. 13-16. (2018)

6. V.A. Zelikov, G.N. Klimova, Yu.V. Strukov, A.Yu. Artemov, D.V. Likhachev Increasing psychological stability of vehicle drivers Studies in Computational Intelligence T. 826 P. 1129-1136. (2019)

7. Yu.I. Lobanova, Differentiation of stereotyped perceptions of road users: determining factors, European Social Science Journal Vol. 2 No. 12 P. 393-402. (2018)

8. E.V. Ageev, E.S. Vinogradov, Principles and methods for evaluating training complexes in the system of professional training of drivers, The world of transport and technological machines No. 3 (70) P. 107-114. (2020)

9. E.V. Ageev, A.N. Novikov, E.S. Vinogradov, Methodology for the application of programmed driver training, The world of transport and technological machines No. 4 (71) P. 75-82. (2020) 
10. E.V. Ageev, E.S. Vinogradov, Application of simulator training in driver training, The world of transport and technological machines No. 2 (69) P. 110-115. (2020)

11. A.P. Makurina, S.V. Shport, A.A. Dubinsky, A.S. Vasilchenko, Features of emotional experiences of professional drivers, depending on the assessment of the traffic situation, Russian Psychiatric Journal No. 3 P. 11-17. (2019) 